\title{
Cultural Challenges When Memorializing Tragedies
}

\author{
Kjell Brataas \\ Ministry of Transportation, Oslo Norway
}

\begin{abstract}
After a tragedy, victims and survivors often desire to memorialize what happened. This can take many forms, and finding the right way often involves a number of challenges. There will usually be differences of opinion among the bereaved, the injured and the uninjured survivors, and cultural aspects and differences play a major role. This presentation provides examples from around the world and hints on bridging the culture gap when memorializing a tragedy.
\end{abstract}

Keywords — crisis communication, family assistance, victim support,

SUGGESTED CITATION: Brataas, K. (2018). Cultural challenges when memorializing tragedies. Proceedings of the International Crisis and Risk Communication Conference (pp. 5-7). Orlando, FL, USA. Nicholson School of Communication. https://doi.org/10.30658/icrcc.2018.2

\section{INTRODUCTION}

How should we memorialize a tragedy? That is a question with no obvious answer, and one that often leads to discussion and controversy. It involves feelings and emotions on many levels, and factors such as geographical location, inscriptions of names and financial matters need to be agreed on. In several instances, finding the right way of memorializing a tragedy involves heated debates, years of planning and in some cases end up in court. Fortunately, there are some best practices from which to learn.

One important lesson from past memorials is to deliberate on the concept of culture. A broad definition should be used, including nationalities, religion, languages and upbringing. Cultural considerations also need to cover factors such as past experiences and expectations of those involved, financial matters, volunteering, donations and leadership. Some come into play right away, and a simple gesture from the person in charge that he or she sees and listens to the victims is a good way to start.

\section{WAYS OF MEMORIALIZING}

Memorializing a tragedy can take many forms:

- Funerals

- Spontaneous vigils

- $\quad$ Ceremonies and anniversaries

- $\quad$ Site visits

- $\quad$ Physical displays

- Charities

- Museums

- Movies

Funerals are the "basic" way of memorializing a death, but after a large-scale tragedy a funeral does usually not suffice. The bereaved, the survivors, the media and the public often demand something more "substantial," and there is a basic need for being able to take part in a more inclusive event than a funeral for an individual family. We often see that in the first few days after a tragedy, people flock to the site - or near the site - where a spontaneous vigil can consist of flowers, letters and candles in memory of those who died. The Pulse shooting in Orlando and the terror in Oslo and Utoya are examples of mass killings that resulted in a sea of flowers that grew in scale and attention in the days after the event. Such a way of memorializing can appear to be easy to organize, but there are many cultural challenges - including when to take it down and what to do with flowers and other materials left at the site. In Norway, all letters left in front of the Oslo Cathedral after 
the terror on July $22^{\text {nd }} 2011$ were digitized and are now stored electronically in the National Archive.

Ceremonies can be a visible and culturally rewarding way of memorializing a tragedy. Often arranged a few weeks after the tragedy, it can include speeches, music and the reading of names of the deceased. Such ceremonies are usually not a one-time occurrence; similar set-ups can be used one, two, three, four and five years after it happened, then again on the $10^{\text {th }}$ anniversary, maybe on the $15^{\text {th }}$ and usually 20 years after. Organizing a ceremony involves cultural differences on many levels, and those in charge need to negotiate between various views and opinions regarding where it should take place, who should participate and what should be said. Again, focus should be on the victims and bereaved, when planning as well as when conducting the ceremony.

Survivors and family members of those who died often wish to see the place of the tragedy and where loved ones died. The Norwegian government has extensive experience in organizing large-scale site visits, as after the tsunami in Asia in 2004, relatives of those who died were invited to an all-expense paid trip to Thailand to see where their family members perished. Similarly, after the terror in Oslo and on Utoya in 2011, authorities in Norway made it possible for survivors (564 people were on Utoya when the shooting started) to spend a day back on the island in August 2011. The next day, the island was open only to the bereaved of the 69 people who were killed [1]. Such site visits involve logistical challenges, cultural differences and financial burdens, but research shows that they work. Several studies by Norwegian psychologists have looked into the outcome of site visits, and their conclusions is that most participants benefit psychologically from taking part. An original research by Dr Trond Heir and Dr Lars Weisath of the Norwegian Center for Violence and Traumatic Stress Studies, concluded that "Considerable improvements in anxiety symptoms were reported and observed in both adults and children" [2].

Physical displays of a memorial can take many forms - and usually a lot of time. The conception phase often lasts several years, as organizers need to agree on details such as location, funding and inscriptions of names. A "record" might be held by a memorial that symbolizes the accident of American Eagle Flight 4184. The crash happened in 1994; the memorial opened in 2014. In addition to the time frame involved, those in charge of planning a memorial need to be aware of major differences of opinion among the bereaved that might surface. And as two recent examples demonstrate, donations from individuals are seldom the solution. After the terror attack in Paris in 2015, the US artist Jeff Koons donated a monumental sculpture to the city of Paris. It was "the brainchild of the US ambassador to France," and it was therefore hard for the city to refuse the offer. However, the price for installing it was estimated at almost four million USD, and its weight of 30 tons meant that the planned site did not have strong enough foundation [3]. Similarly, in London, controversy erupted when a group of private individuals and historians wanted to put up a second memorial for $9 / 11$. They suggested a GBP 600,000 sculpture made by steel girders recovered from the wreckage of the World Trade Center be put up in Potters Field Park, but a town meeting to discuss the proposal (two months after planning permission had been granted) ended in much criticism about the planning process and the lack of involving actual family members and neighbours [4]. After being stored in a warehouse for several months, the finished art work is now on display in a remote location of the Olympic Park. In Norway, there has been much discussion about a proposed massive art work - "Memory Wound" - near the island of Utoya. Neighbours protested vigilantly, and after threatening to take the case to court, it was agreed to go forward with a much smaller and less intruding memorial. The artist and others protested, saying that "it amounts to a denial of the role of art and culture in helping people process traumatic events" and that "such decisions are too important to leave to politicians" [5]. However, on the island of Utoya itself, a steel monument is already in place. As its shape is circular, and with all names printed equally, the monument is seen as a symbol of democracy - exactly what the terrorist wanted to attack.

Charities in the wake of a tragedy are probably more common in the US than elsewhere in the world. They can mean a new beginning for victims, and if handled correctly a charity can become a symbol for a city united and people willing to help each other. One of the best examples is the One Fund Boston, which was initiated less than 24 hours after the terror attack on the Boston Marathon. It received more than USD 80 million from 200,000 individuals, groups and businesses. It is important to be aware, however, that fake charities often appear right after a tragedy, and that government officials and those in charge therefore need to be aware of such attempts at scams and rip-offs.

In several instances, a museum is a good way of preserving memories of those who died and the tragedy itself. At Ground Zero in New York a museum of the terror attack is found near the outside memorial, and in Norway there are museums commemorating the terror on July $22^{\text {nd }} 2011$ in Oslo as well as on the island of Utoya. Both museums have a timeline as one of its main exhibits, showcasing when the bomb went off, news reports and social media messages from young people hiding from the terrorist on the island.

Not necessarily in the interest or in cooperation with victims, several disasters have been made into feature length movies. Their focus often stirs controversy and debate, and scholars, victims and the public disagree amongst themselves about when (if ever) is a good time for such a movie to be released. In 2018, several movies and a TV series will depict the terror in Norway. "Utoya 22 July" by Erik Poppe is already in theaters, but it was first shown to members of the support group so that they could see it - and advice others - before its main release. Similarly, director Paul Greengrass worked with the support group when planning his movie based on the book "One of us" by Asne Seierstad. Greengrass is not new to this kind of film making; he was nominated for an Oscar for his movie "United 93" about the hijacking of a plane on 9/11. Prior to production, he also worked closely with the bereaved. 


\section{CHALLENGES}

Based on the examples above, it is easy to see that memorializing a tragedy involves many cultural challenges. By its very nature, a memorial service or a physical display will invoke human feelings and emotions, and it is therefore sometimes impossible to reach a solution everyone can agree on. Organizers also need to discuss the question "Who is a victim?" which often proves more difficult than one could foresee. Combined with financial matters such disputes can become personal, heated and open to the public.

Traditional and social media also need to be considered when planning a memorial. Newspapers, TV and radio often want to provide live coverage from a memorial service or site visit, but at the same time participants have a need for a private event which is not disrupted by journalists and photographers. That was the case on Utoya in Norway in August 2011, when survivors and bereaved visiting the island told organizers they did not want to encounter any kind of media representatives on the island. To provide for both parties' wishes, the government therefore rented a farm on the mainland, which had a view of Utoya, and turned it into a media camp.

Social media provide a new tool for victims to organize and spread their views and opinions. When organizing a memorial, it is therefore important to follow what is being said on Twitter and open Facebook pages, and to also use these channels for giving official information and updates.

\section{CONCLUSION}

Memorializing a tragedy has many merits, and in most instances, it is a rewarding experience for victims, the bereaved, the public, the media and government or private organizers. To make it work as smoothly as possible, these hints should be considered:

- Encourage the establishment of support groups, and involve the group in the planning process

- $\quad$ Respect that victims are individuals, and do not expect everyone to agree on a solution

- Downplay the role of VIPs and dignitaries, and focus on victims, the bereaved and survivors when planning

\section{Author Biography}

Kjell Brataas is a senior communications advisor with the Ministry of Transportation in Norway. He holds a bachelor degree in Communications from the University of Texas at Austin. He has recently written a book called "Crisis Communication - Case Studies and Lessons Learned from International Disasters" published by Routledge. kbrataas@online.no.

\section{REFERENCES}

[1] Brataas, K. 2018. Crisis Communication - Case Studies and Lessons Learned from International Disasters, New York, NY: Routledge.

[2] Heir, T and Weisath, L (2006). Back to Where It Happened: Self-Reported Symptom Improvement of Tsunami Surivors who Returned to the Disaster Area. Prehospital and Disaster Medicine, 2006 Mar-Apr;21(2):59-63.

[3] Donadio, R. (2017) How Jeff Koons's gift to Paris is riddled with problems The Independent. https:/www.independent.co.uk/arts-entertainment/art/features/how-jeff-koons-gift-to-paris-is-riddled-with-problemsa7808351.html

[4] London SE1 Website Team (2011) Simon Schama clashes with opponents of Potters Fields Park 9/11 artwork http://www.london-se1.co.uk/news/view/5131

[5] Henley,J. (2017). Norway embroiled in row over move to scrap Utøya memorial. The Guardian. https://www.theguardian.com/world/2017/jun/29/artist-hits-back-over-norways-decision-to-scrap-utya-memorial 